\title{
Synthesis and Application of a Spirocompound as Clean Viscosity-Reducer for Crude Oil
}

\author{
Shijun Chen, ${ }^{1,2}$ Kang Zhao, ${ }^{1}$ Gang Chen, ${ }^{2}$ Li Bai, ${ }^{1}$ and Lajun Feng' \\ ${ }^{1}$ School of Materials Science and Engineering, Xian University of Technology, Xi'an 710048, China \\ ${ }^{2}$ College of Chemistry and Chemical Engineering, Xi'an Shiyou University, Xian, Shaanxi 710065, China \\ Correspondence should be addressed to Shijun Chen; csjun@xsyu.edu.cn and Gang Chen; gangchen@xsyu.edu.cn
}

Received 16 November 2015; Revised 13 January 2016; Accepted 20 January 2016

Academic Editor: Barbara Gawdzik

Copyright (C) 2016 Shijun Chen et al. This is an open access article distributed under the Creative Commons Attribution License, which permits unrestricted use, distribution, and reproduction in any medium, provided the original work is properly cited.

\begin{abstract}
Heavy oil transportation has become a highly technical operation facing complex difficulties. One of the major difficulties in the pipeline transportation is the high viscosity that requires efficient and economical ways to deal with. The typical polymer viscosity reducers are a negative problem during oil refinement process for their chemical properties. The objective of this study is to seek small molecular compound, different from the traditional polymers, to reduce the viscosity of the crude oil. In this work, a spirocompound, 3,9-diphenyl-2,4,8,10-tetraoxa-spiro[5.5] undecane, was synthesized catalyzed by zeolite and modified zeolite, and the product was fully characterized by NMR, MS, and TG. Then, it was used as viscosity reducer for crude oil. The factors such as dosage and temperature on the viscosity behavior have been studied. The results showed a significant viscosity reduction at different temperature, and the most economical dosage is $500 \mathrm{ppm}$. The multiphenyl groups can interact with asphaltene by $\pi-\pi$ stacking, and the spirostructure can fix the stacking in different direction, which can prevent the agglomeration of wax crystals.
\end{abstract}

\section{Introduction}

Oil transportation has become a complex and highly technical operation. One of the major difficulties in the pipeline transportation is the high viscosity that requires efficient and economical ways to deal with [1-3]. Therefore, different methods are used in order to reduce the viscosity of the heavy crude for the pipeline transportation $[4,5]$, such as dilution with lighter crudes or alcohols, heating, and the use of chemical additives. The typically chemical additives are polymers having a wax-like paraffinic part and a polar component, such as homo- and copolymers of alpha olefins [6], polyalkyl acrylates and methacrylates [7-9], alkyl esters of styrene-maleic anhydride copolymers [10-12], ethylenevinyl acetate copolymers [13], and alkyl fumarate-vinyl acetate copolymers [14]. But the long molecular chain, large molecular weight, and high thermostability of these polymers are a negative problem during oil refinement process [15]. So it is necessary to seek small molecular crude oil additives. In this paper, a spirocompound, 3,9-diphenyl-2,4,8,10-tetraoxaspiro[5.5] undecane, was managed to be synthesized and evaluated as a viscosity reducer for crude oil.

\section{Experimental}

2.1. Materials. Chemicals were either prepared in our laboratories or purchased from Merck, Fluka, and Aldrich Chemical Companies. All yields refer to isolated products. The products were characterized by comparison of their physical data with those of known samples or by their spectral data. NMR spectrum was recorded in the stated solutions, on a Bruker Drx-500 spectrometer, operating at $500 \mathrm{MHz}$ for ${ }^{1} \mathrm{H} ; \delta$ values are reported in ppm and $J$ values in hertz. Mass spectrum was recorded on a Micromass Platform II spectrometer, using the direct-inlet system operating in the electron impact (EI) mode at $75 \mathrm{eV}$. Thermal analysis was performed on a TGA/SDTA851e Thermal Analyzer, where the heating rate was $10 \mathrm{~K} \mathrm{~min}^{-1}$ in the range of $298-880 \mathrm{~K}$.

2.2. Method. Initially, the crude oil was homogenized by shaking it for an hour to ensure that the physical properties of the heavy crude oil are the same. After homogenization, the crude oil was used for measurements. The crude oil samples used in this study were obtained from Jinghe Oilfield, China. 


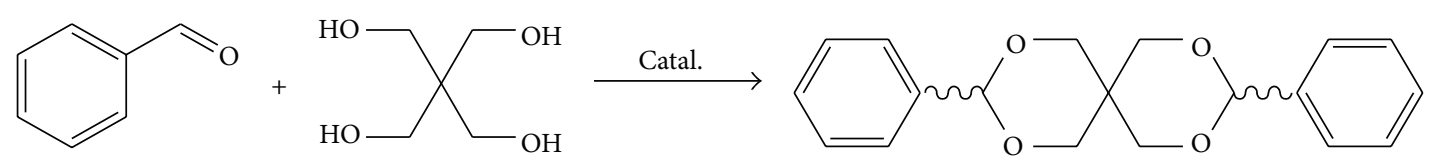

Scheme 1: Synthesis of 3,9-diphenyl-2,4,8,10-tetraoxa-spiro[5.5] undecane.

TABLE 1: The group compositions of the crude oil.

\begin{tabular}{lccc}
\hline Saturated HC (\%) & Aromatic HC (\%) & Resin (\%) & Asphaltene (\%) \\
\hline 54.04 & 25.88 & 19.24 & 0.84
\end{tabular}

The density of the used heavy crude oil is $905 \mathrm{~kg} / \mathrm{m}^{3}$ at $15^{\circ} \mathrm{C}$, and the pour point is $34.8^{\circ} \mathrm{C}$. The group compositions of the crude oil are shown in Table 1.

\subsection{Synthesis of 3,9-Diphenyl-2,4,8,10-tetraoxa-spiro[5.5]un-} decane. Benzaldehyde and pentaerythritol were added in a flask with the molar ratio of $2: 1$, and the toluene was added as the water carrier and the solvent. 5\% (wt) solid acid, zeolite, was added as catalyst. The mixture was refluxed until no water can be carried out and was cooled to room temperature. The zeolite was filtrated, and the solvent was evaporated to produce the crude product. Recrystallized in methanol, the pure product was obtained as colorless block. The reaction is described in Scheme 1. ${ }^{1} \mathrm{H} \mathrm{NMR}\left(500 \mathrm{MHz}, \mathrm{CDCl}_{3}\right) \delta$ : $7.22 \sim 7.52(\mathrm{~m}, 10 \mathrm{H}), 5.41(\mathrm{~s}, 2 \mathrm{H}), 4.72(\mathrm{~d}, J=7.5 \mathrm{~Hz}, 2 \mathrm{H})$, $3.88(\mathrm{~d}, J=7.5 \mathrm{~Hz}, 2 \mathrm{H}), 3.72(\mathrm{~d}, J=7.0 \mathrm{~Hz}, 2 \mathrm{H}), 3.63(\mathrm{~d}$, $J=7.0 \mathrm{~Hz}, 2 \mathrm{H})$; IR (KBr) v: 3010, 2985, 2885, 1566, 1529, 1480, $1378,1116 \mathrm{~cm}^{-1}$.

2.4. Viscosity of the Treated Crude Oil. Crude oil sample was doped with cyclohexanone pentaerythritol ketal butanol solution with concentrations of $100,300,500,800$, or $1000 \mathrm{ppm}$. The viscosity measurements were carried out at test temperatures of $30-50^{\circ} \mathrm{C}$, representative of temperatures greater than, equal to, and lower than the pour point of the crude oil, respectively.

\section{Results and Discussion}

3.1. Synthesis. 3,9-Diphenyl-2,4,8,10-tetraoxa-spiro[5.5]undecane has been synthesized using $\mathrm{I}_{2}$ as catalyst with high yield, but it is complex to remove the catalyst after the reaction [16]. In this synthesis, three kinds of zeolite and corresponding sulfonated species were screened, and the results were shown in Figure 1. From the results, it can be found that the catalytic activity is quite different. For the zeolite, $\mathrm{NaY}$ and ZSM-5 are active for this reaction, and ZSM-5 is the most effective one with the yield of $97.2 \%$, compared with $3.9 \%$ for $4 \mathrm{~A}$. After the sulfonation, all the yields are increased. The yield of 3,9-diphenyl-2,4,8,10tetraoxa-spiro[5.5] undecane increases to $95.0 \%, 98.2 \%$, and $25.0 \%$, respectively, which may be due to the increased acidity by sulfonation.

In the following work, the effect of the dosage of ZSM-5 on the yield of 3,9-diphenyl-2,4,8,10-tetraoxaspiro[5.5] undecane was investigated by varying the dosage

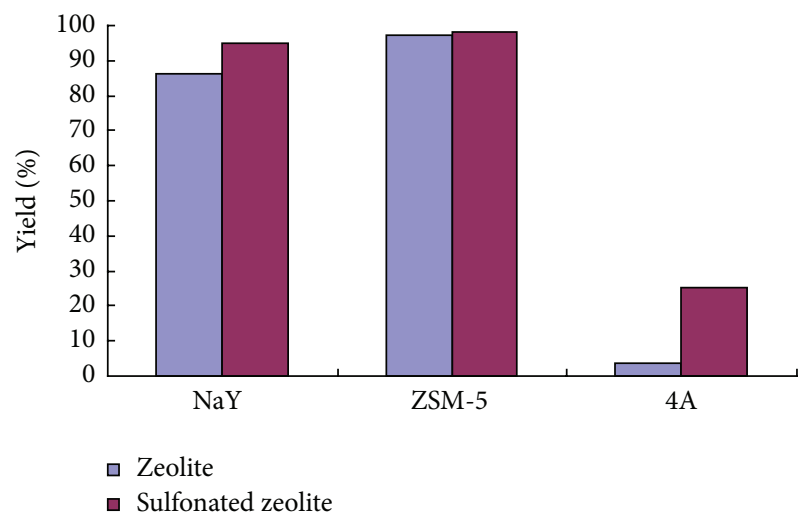

Figure 1: The yield of 3,9-diphenyl-2,4,8,10-tetraoxa-spiro[5.5]undecane catalyzed by zeolite.

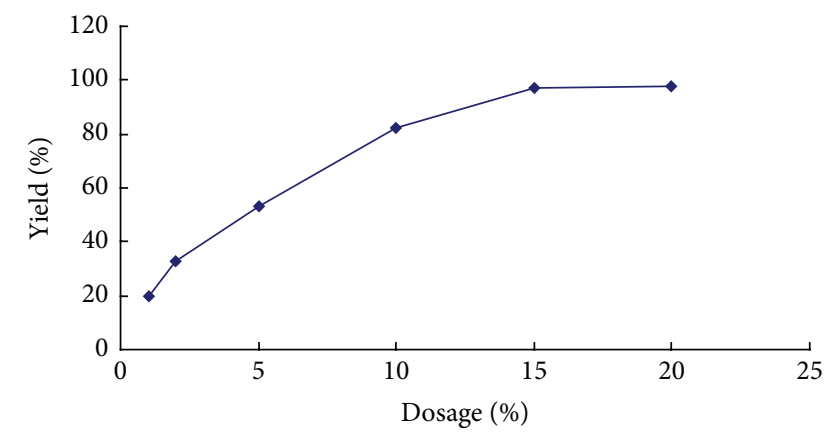

FIGURE 2: The effect of the dosage of ZSM-5 on the yield of 3,9diphenyl-2,4,8,10-tetraoxa-spiro[5.5] undecane.

from $1 \%$ to $20 \%$, and the results are shown in Figure 2. From the results, it can be seen that the low amount of catalyst is not efficient to cause the reaction to happen. With increasing the amount to $15 \%$, yield of 3,9-diphenyl-2,4,8,10-tetraoxaspiro[5.5] undecane increases up to $97.2 \%$. The reason for the increased conversion with an increase in the catalyst weight should be attributed to the increase in number of catalytically active sites provided by large amount of ZSM-5. Further increasing the amount of catalyst to $20 \%$, the yield does not increase further.

3.2. Isomers. For the fixed spirostructure, the 3,9-diphenyl2,4,8,10-tetraoxa-spiro[5.5] undecane has four kinds of isomers, shown in Figures 3(a)-3(d). In molecular (a) and (d), the two phenyl groups are trans-conformation, and, in molecular (b) and (c), the two phenyl groups are cisconformation. It should be noticed that molecular (a) can transfer to molecular (d) by rotating with $180^{\circ}$, and molecular 


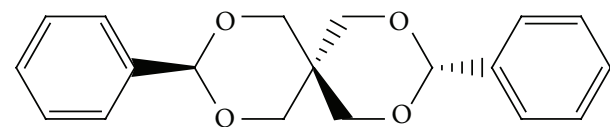

(a)

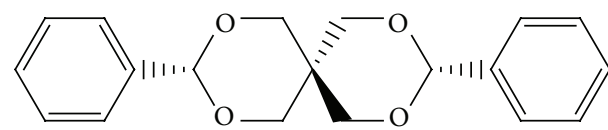

(c)

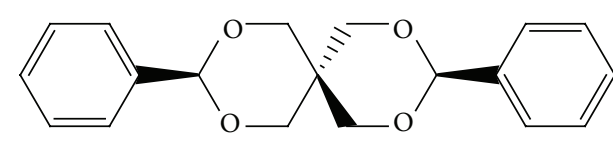

(b)

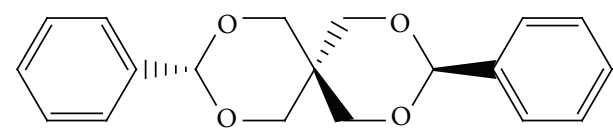

(d)

Figure 3: The isomers of 3,9-diphenyl-2,4,8,10-tetraoxa-spiro[5.5] undecane.

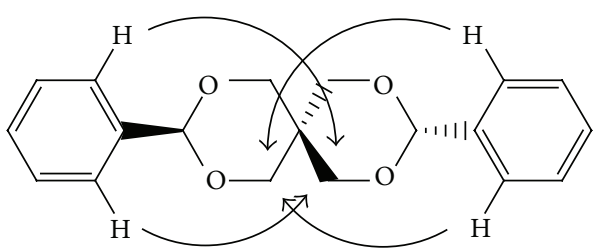

(a)

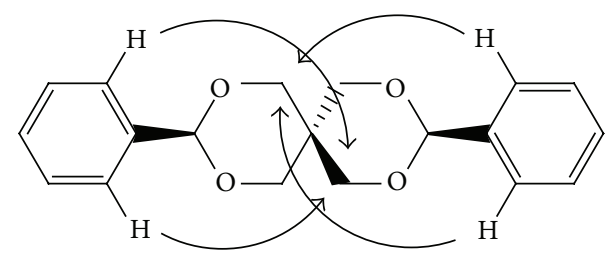

(b)

FIgURE 4: The H-H correlations of isomer (a) and (b).

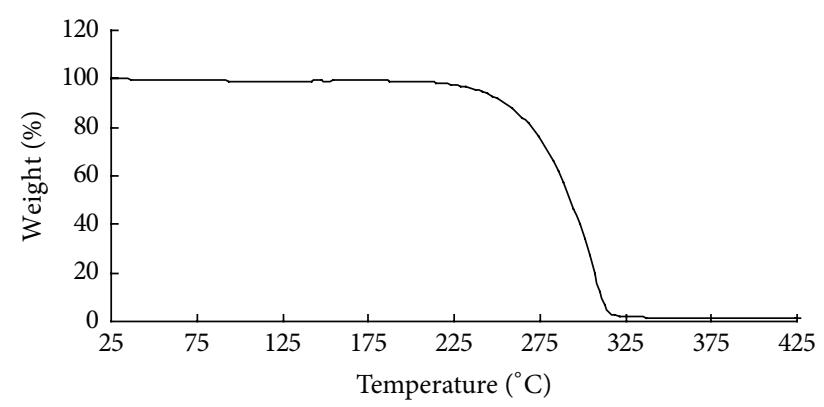

FIGURE 5: The TGA curves of 3,9-diphenyl-2,4,8,10-tetraoxaspiro[5.5] undecane.

(b) can transfer to molecular (c) by the same way as well. So there are two kinds of isomers in fact.

The NMR spectrum of 3,9-diphenyl-2,4,8,10-tetraoxaspiro[5.5] undecane shows that multiple peaks at $\delta$ 7.22 7.52 $(\mathrm{m}, 10 \mathrm{H})$ are due to the $\mathrm{H}$ of phenyl groups. The single peak at $5.41(\mathrm{~s}, 2 \mathrm{H})$ is due to the $\alpha-\mathrm{H}$ of the phenyl group, which is inducted by two $\mathrm{O}$ atoms resulting in the relatively high chemical shift. For the four $\mathrm{CH}_{2}$ groups, it seems that the four groups are under the same chemical condition and will have the same chemical shift but show four different chemical shifts. Analyzing the stereogenic configuration of isomers (a) and (b) (as shown in Figure 4), it can be found, with the fixed spirostructure, that $\mathrm{H}$ atoms of the phenyl groups can correlate with certain stereogenic $\mathrm{CH}_{2}$ group, which can lead to two kinds of $\mathrm{CH}_{2}$ group in each isomer. So as a result, there are four kinds of $\mathrm{CH}_{2}$ groups corresponding to four chemical shifts.

3.3. Thermal Gravimetric Analysis. The TGA analysis of 3,9diphenyl-2,4,8,10-tetraoxa-spiro[5.5] undecane was shown in Figure 5. It indicates that it is stable below $200^{\circ} \mathrm{C}$, but as

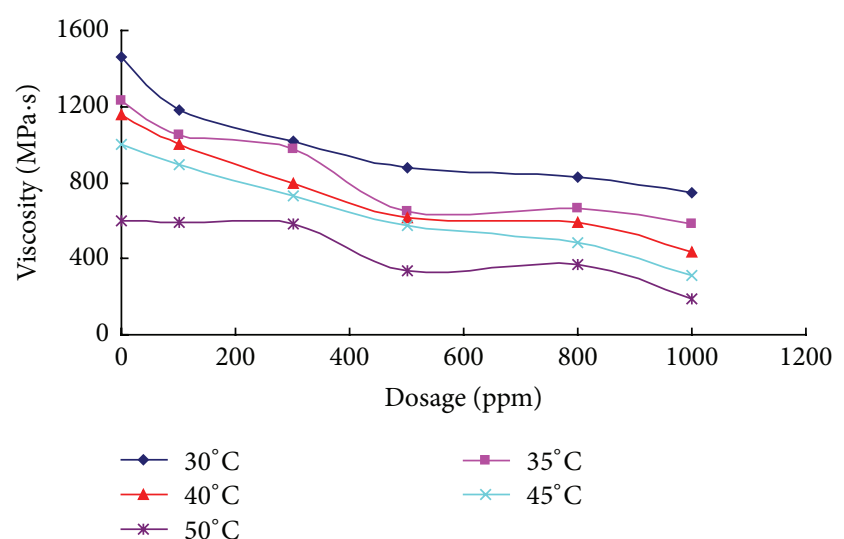

FIgURE 6: The relation of dosage and viscosity.

the temperature increases above $205^{\circ} \mathrm{C}$, the crystal starts to lose weight sharply. The first stage of weight loss is only about $1.2 \%$ between 25 and $205^{\circ} \mathrm{C}$, which may correspond to the loss of absorbed solvent. The second stage of weight loss is about $96 \%$ between 205 and $319^{\circ} \mathrm{C}$, which corresponds to the decomposition of 3,9-diphenyl-2,4,8,10tetraoxa-spiro[5.5] undecane. Above $319^{\circ} \mathrm{C}$, the remaining weight ratio is only $<2.7 \%$, which corresponds to the residues of carbon deposit. The thermal performance indicates 3,9diphenyl-2,4,8,10-tetraoxa-spiro[5.5] undecane easy decomposition under relative lower temperature than that of polymer, which means it may be a cleaner crude oil additive than polymers additives.

3.4. Viscosity-Reducing Performance. 3,9-Diphenyl-2,4,8,10tetraoxa-spiro[5.5] undecane was evaluated as a viscosity reducer for a crude oil, and the results were shown in Figures 6 and 7. Figure 6 shows the crude oil viscosity as a function 


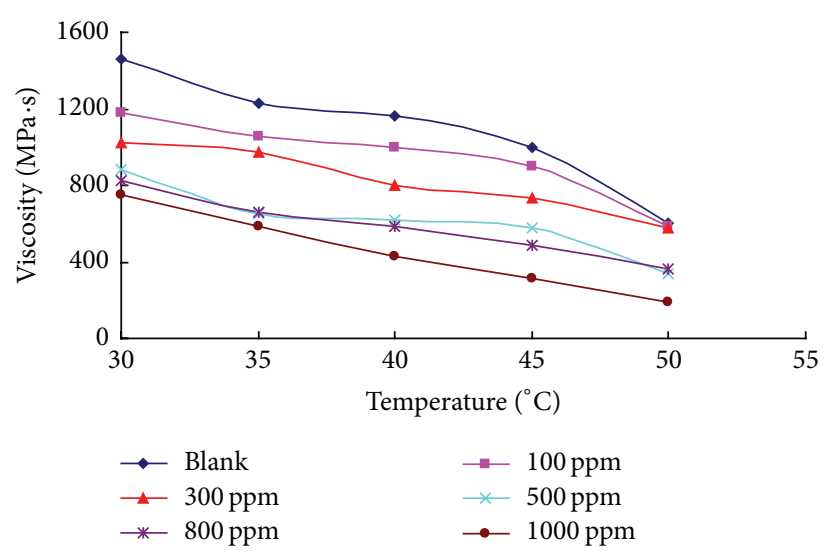

FIGURE 7: The relation of temperature and viscosity.

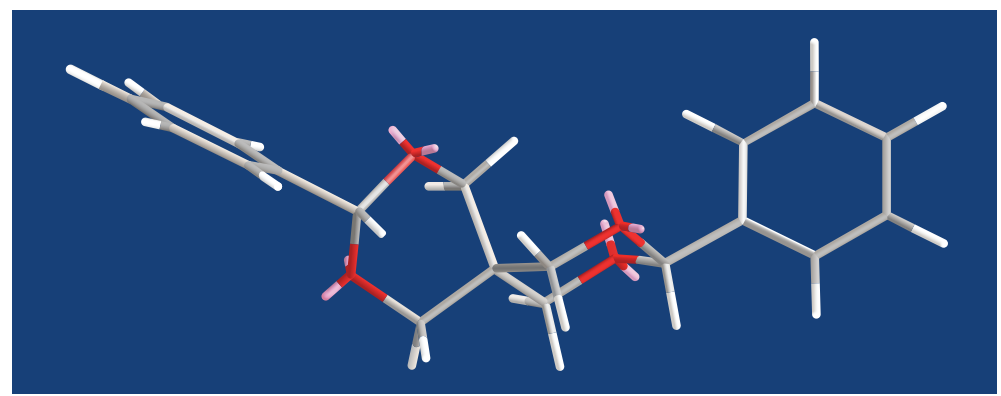

Isomer (a)

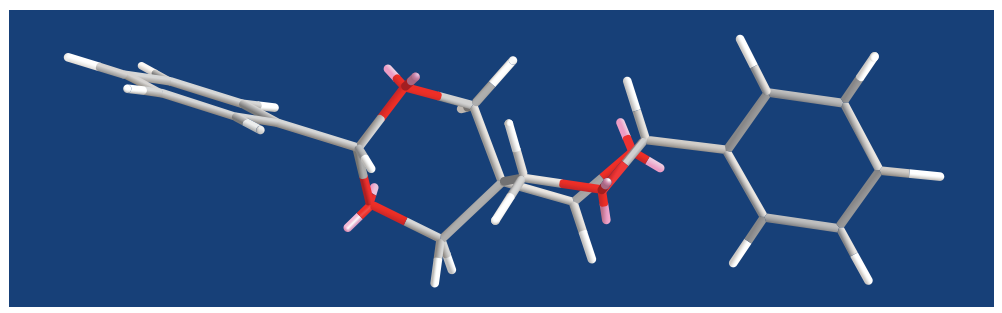

Isomer (b)

FIGURE 8: The steady conformations of isomers (a) and (b).

of the dosage under different temperature, respectively. It reduces the crude oil viscosity depending on dosage. At each temperature, the higher the concentrations were, the better the reduction was observed obviously with the dosage below $500 \mathrm{ppm}$. While the dosage rises up to over $500 \mathrm{ppm}$ $(800 \mathrm{ppm}$ and $1000 \mathrm{ppm})$, the viscosity does not reduce effectively. So the economical use of this kind of viscosity reducer is $500 \mathrm{ppm}$. Under this condition, the viscosity was reduced from $1460 \mathrm{mPa} \cdot \mathrm{s}$ to $882 \mathrm{mPa} \cdot \mathrm{s}$ at the relative low temperature of $30^{\circ} \mathrm{C}$. If the $1000 \mathrm{ppm}$ was used, the viscosity can be reduced to $186 \mathrm{mPa} \cdot \mathrm{s}$ at the $50^{\circ} \mathrm{C}$, which can be a usable additive in the present China pipeline transports crude oil. Also, Figure 7 shows the crude oil viscosity is a function of the temperature in the presence of $100,300,500$, 800 , and $1000 \mathrm{ppm}$, respectively. The behavior of reducing the viscosity after addition of 3,9-diphenyl-2,4,8,10-tetraoxaspiro[5.5] undecane can thus be attributed to the chemical structure.
The slight polarity of the benzene ring and the presence of high polarity of oxygen play a role $[17,18]$. The steady conformations of isomers (a) and (b) were expressed in Figure 8 , which were simulated by a minimized energy of MM2 in Chem 3D. In both conformations, the two phenyl groups display a dihedral angle of about $90^{\circ}$. The multiphenyl groups can interact with asphaltene by $\pi-\pi$ stacking [19], and the spirostructure can fix the stacking in different direction, which can prevent the agglomeration of wax crystals in crude oil.

\section{Conclusion}

The objective of this study is to investigate the small molecular compounds, different from the traditional polymers, to reduce the viscosity of the crude oil. In this work, 3,9-diphenyl-2,4,8,10-tetraoxa-spiro[5.5] undecane was synthesized under optimized conditions. Then, it was evaluated 
as viscosity reducer for crude oil. A wide range of temperature was covered in this study to examine the effect of temperature on the flow behavior of the crude oil. The results showed that the viscosity was reduced from $1460 \mathrm{mPa} \cdot \mathrm{s}$ to $882 \mathrm{mPa} \cdot \mathrm{s}$ at the relative low temperature of $30^{\circ} \mathrm{C}$ with the dosage of $500 \mathrm{ppm}$; the viscosity can be reduced to $186 \mathrm{mPa} \cdot \mathrm{s}$ at the $50^{\circ} \mathrm{C}$ and with the dosage of $1000 \mathrm{ppm}$. This work found that the small spirocompound rather than the polymers can be used as viscosity reducer for crude oil.

\section{Conflict of Interests}

The authors declare that there is no conflict of interests regarding the publication of this paper.

\section{Acknowledgment}

This work was financially supported by the grants from the National Natural Science Foundation of China (21376189).

\section{References}

[1] E. M. Newberry, "Chemical effects on crude oil pipeline pressure problems," Journal of Petroleum Technology, vol. 36, pp. 779-786, 1984.

[2] C. R. Price, "Flow improvers for waxy crudes," Journal of the Institute of Petroleum, vol. 57, pp. 106-109, 1971.

[3] D. Chanda, A. Sarmah, A. Borthakur, K. V. Rao, B. Subrahmanyam, and H. C. Das, "Alkyl fumarate-vinyl acetate copolymer as flow improver for high waxy Indian crude oils," Energy Fuels, vol. 10, no. 3, pp. 844-848, 1996.

[4] X. Gu, Y. Ma, and G. Chen, "Preparation and evaluation of polymeric pour point depressant for crude oil," Advanced Materials Research, vol. 524-527, pp. 1706-1709, 2012.

[5] A. M. Al-Sabagh, M. R. Noor El-Din, R. E. Morsi, and M. Z. Elsabee, "Styrene-maleic anhydride copolymer esters as flow improvers of waxy crude oil," Journal of Petroleum Science \& Engineering, vol. 65, no. 3-4, pp. 139-146, 2009.

[6] A. A. Hafiz and T. T. Khidr, "Hexa-triethanolamine oleate esters as pour point depressant for waxy crude oils," Journal of Petroleum Science and Engineering, vol. 56, no. 4, pp. 296-302, 2007.

[7] P. Juyal, T. Cao, A. Yen, and R. Venkatesan, "Study of live oil wax precipitation with high-pressure micro-differential scanning calorimetry," Energy and Fuels, vol. 25, no. 2, pp. 568-572, 2011.

[8] A. L. C. Machado, E. F. Lucas, and G. González, "Poly(ethyleneco-vinyl acetate) (EVA) as wax inhibitor of a Brazilian crude oil: oil viscosity, pour point and phase behavior of organic solutions," Journal of Petroleum Science and Engineering, vol. 32, no. 2-4, pp. 159-165, 2001.

[9] J. W. Qian, G. R. Qi, D. L. Han, and S. L. Yang, "Influence of incipient chain dimension of EVA flow improver on the rheological behaviour of crude oil," Fuel, vol. 75, no. 2, pp. 161$163,1996$.

[10] J. B. Taraneh, G. Rahmatollah, A. Hassan, and D. Alireza, "Effect of wax inhibitors on pour point and rheological properties of Iranian waxy crude oil," Fuel Processing Technology, vol. 89, no. 10, pp. 973-977, 2008.
[11] G. Chen, Y. Tang, and J. Zhang, "Synthesis and application of polyaminoamide as new paraffin inhibitor from vegetable oil," Chemistry Central Journal, vol. 5, article 82, 2011.

[12] K. S. Pedersen and H. P. Ronningsen, "Influence of wax inhibitors on wax appearance temperature, pour point, and viscosity of waxy crude oils," Energy \& Fuels, vol. 17, no. 2, pp. 321-328, 2003.

[13] G. A. Holder and J. Winkler, "Crystal-growth poisoning of nparaffin wax by polymeric additives and its relevance to polymer crystallization mechanisms," Nature, vol. 207, no. 4998, pp. 719721, 1965.

[14] Y. Song, T. Ren, X. Fu, and X. Xu, "Study on the relationship between the structure and activities of alkyl methacrylatemaleic anhydride polymers as cold flow improvers in diesel fuels," Fuel Processing Technology, vol. 86, no. 6, pp. 641-650, 2005.

[15] A. G. Lucas, Modern Petroleum Technology, John Wiley \& Sons, London, UK, 2000.

[16] R. B. Wei, J. Zhang, S. Z. Chen, and Y. Liang, "Synthesis and structure characterization of poly-acetal-spiro-vic-diether," Chinese Journal of Organic Chemistry, vol. 25, no. 1, pp. 116-119, 2005.

[17] A. E. Kuzmić, M. Radošević, G. Bogdanić, V. Srića, and R. Vuković, "Studies on the influence of long chain acrylic esters polymers with polar monomers as crude oil flow improver additives," Fuel, vol. 87, no. 13-14, pp. 2943-2950, 2008.

[18] D. Chanda, A. Sarmah, A. Borthakur, K. V. Rao, B. Subrahmanyam, and H. C. Das, "Combined effect of asphaltenes and flow improvers on the rheological behaviour of Indian waxy crude oil," Fuel, vol. 77, no. 11, pp. 1163-1167, 1998.

[19] I. Suryanarayana, K. Venkateswara Rao, S. Ranjan Duttachaudhury, B. Subrahmanyam, and B. Kumar Saikia, "Infrared spectroscopic studies on the interactions of pour point depressants with asphaltene, resin and wax fractions of Bombay high crude," Fuel, vol. 69, no. 12, pp. 1546-1551, 1990. 

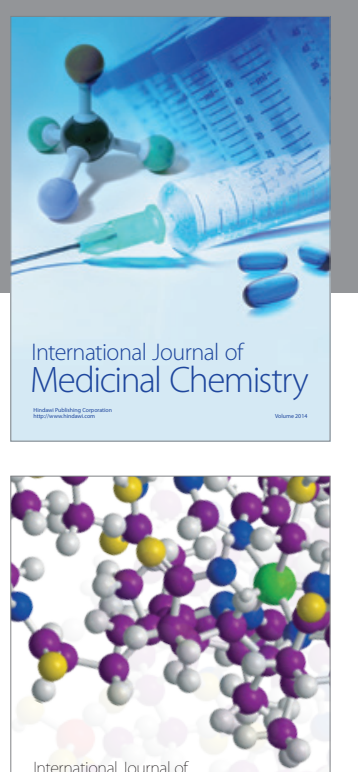

Carbohydrate Chemistry

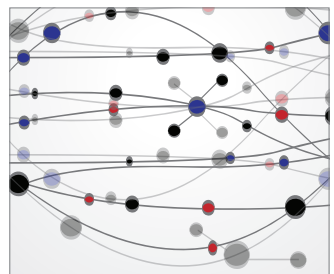

The Scientific World Journal
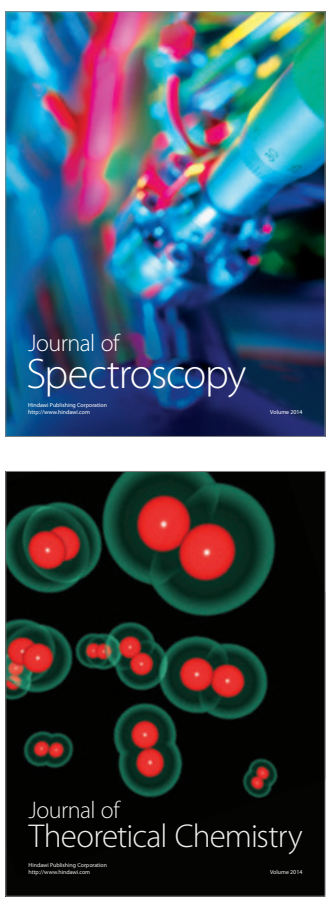
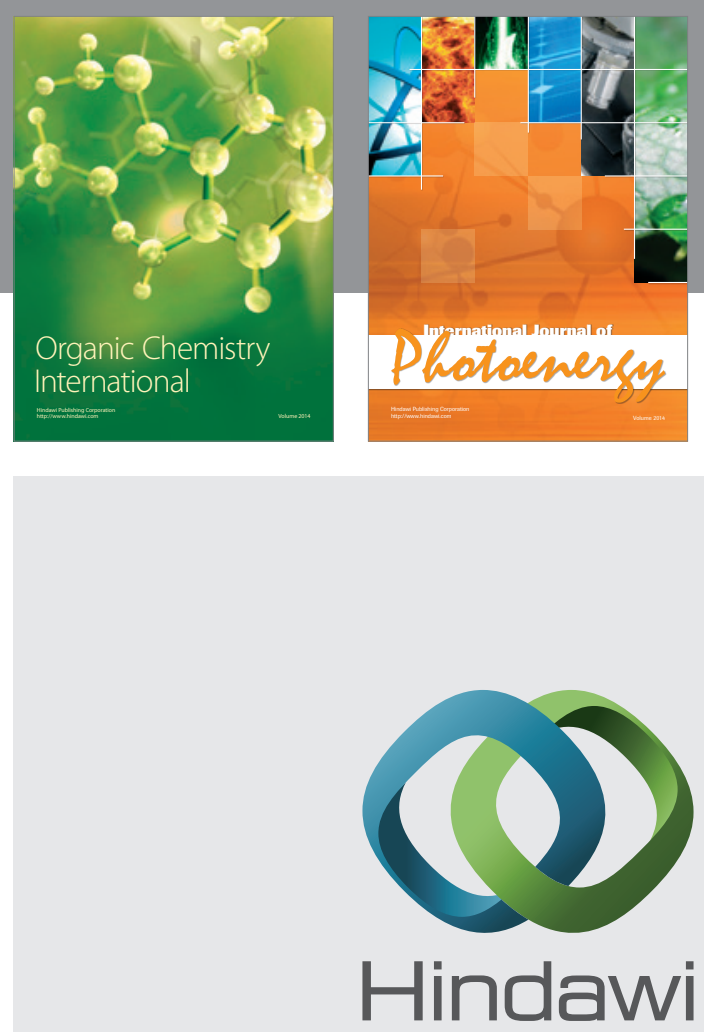

Submit your manuscripts at

http://www.hindawi.com

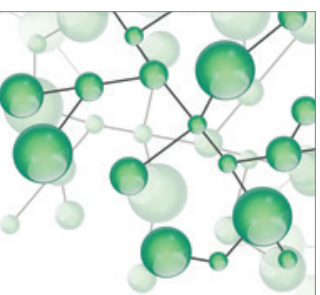

International Journal of

Inorganic Chemistry

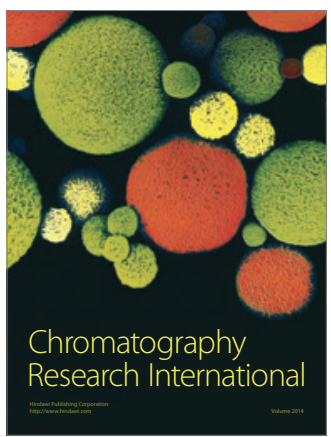

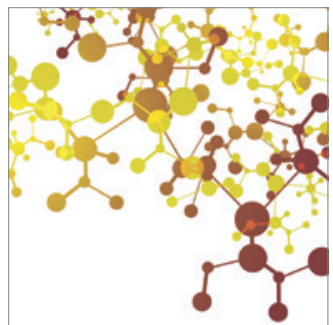

Applied Chemistry
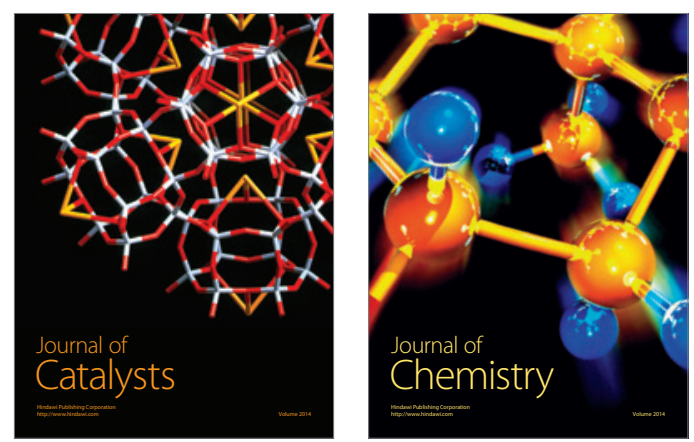
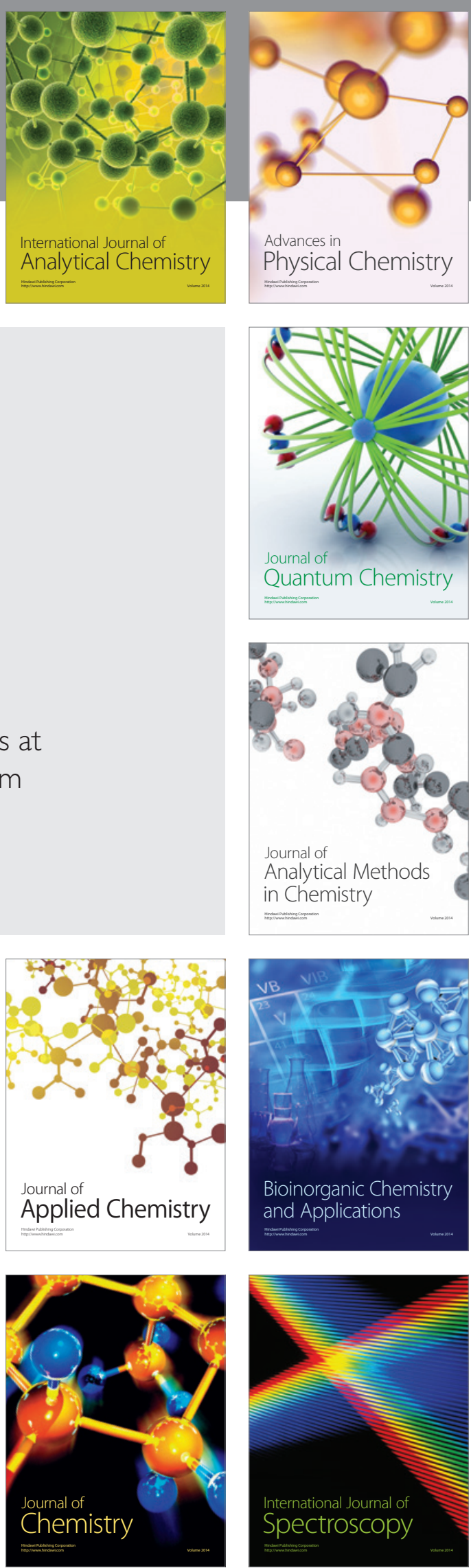